\title{
On-Line Learning Assessment: Egyptian Universities as a Case Study
}

\author{
Salwa Thabet Mekky
}

\begin{abstract}
This article presents results of a study on the level of satisfaction of graduate and undergraduate students, instructors and higher education quality assurance experts with respect to online learning in the field of social sciences at Egyptian universities. A random sample of 577 students, 101 instructors and 6 quality experts participated in the survey. Results convey considerable variations between students affiliated to state universities, a $50 \%$ level of dissatisfaction on online learning compared to a $35 \%$ level of dissatisfaction to their counterparts at private universities, a one of the key indicators for the success of institutions to in shift from conventional to online learning approach. The study presents skepticism concerning conformance of fully online learning approach with academic quality assurance requirements and intended learning outcomes. Recommended policies aim for improvements in challenges related to environmental and technological variables such as the poor internet infrastructure and simultaneously the lack of training and application in Internet usage. Policies are pushing forward with drivers of satisfaction in distance learning instructional design, capacity building, integrative international academic quality measures to develop on-line learning practices in higher education in Egypt ensuring a boost stakeholders' satisfaction.
\end{abstract}

Index Terms-Online approach, digital learning, hybrid learning, higher education, distance learning.

\section{INTRODUCTION}

According to global indicators, more than $60 \%$ of the world's population use the internet and $53 \%$ use social media networks, while around $67 \%$ use cell phones; in addition to 2.5 billion using Facebook and 6 billion using zoom meetings, snapshots and other applications [1]. Since covid-19 pandemic, distance learning has taken the world by storm and, in response, has become a global trend in higher education. In spite of the fact that, prior COVID-19, there has been already a massive growth in education technology, with global education technology investments reaching US\$ 18.66 billion in 2019, and 2025 projections indicate that the overall market for online education is expected to reach US\$ 350 billion; including virtual tutoring, video conferencing platforms, language applications, or online learning software [2].Most renowned international universities have started to develop online programs and curricula attenuating the need for physical space which has been replaced by digital platforms reducing investment costs in education on one hand, while providing more free time for students on the other [3].

Manuscript received April 12, 2021; revised June 4, 2021.

Salwa Thabet Mekky is with Future University in Egypt, Cairo, Egypt (e-mail: sthabet@fue.edu.eg).
Some believe that the sudden and unplanned shift to online learning might lead to poor learning outcomes and educational environment unconducive to sustainable development, while others believe that such experience might lead us to come up with a new innovative version of hybrid education which integrates online learning practices into higher education system turning it to become more effective.

The dramatic shift in how students learn and how they are taught especially for those countries where most accredited educational programs are conventional campus-based, such as in the case of Egypt, poses a great uncertainty concerns with respect to the quality and effectiveness of distance learning. Since Covid-19 crisis has hit the globe, university students in Egypt have been taught either fully or partially/hybrid online courses in response to government policies. This dramatic sudden shift from face-to-face to distance learning has stimulated a dire need to assess the process of shifting to online education. In this context, the study investigates the level of satisfaction or dissatisfaction of major stakeholders, including, students, instructors, and quality assurance experts with respect to a number of critical success factors: convenience, interaction, quality and structure of on-line materials, etc. In addition, the study also assesses perceptions of the different stakeholders concerning learning outcomes of both on-line and conventional campus-based learning. Analysis of results might contribute to improvements in distance learning instructional design and hence develop on-line learning practices which in turn could influence student retention and improve learning outcomes.

\section{A. Hypothesis}

"The COVID-19 pandemic has changed education forever" [2]. Higher education has changed dramatically, with the distinctive rise of distance learning and with a significant surge in the usage of digital platforms, whereby teaching is undertaken remotely and on multiple available digital platforms. With this sudden shift away from conventional campus-based learning in most of the globe, many people are wondering whether the adoption of online learning policy will continue to persist post-pandemic, and how such a shift would impact the educational environment and human capital competencies. The study believes that the current structure of online learning in Egypt does might risk equipping students with intended learning outcomes equivalent to those achieved via campus-based learning; and hence might negatively affect their prospected employability in the labor market. Level of satisfaction of stakeholders with respect to online education could be a valid success measure.

\section{B. Research Questions}


The study attempts to answer the following major questions:

1) What is distance learning as a global trend? And what are its types?

2) How satisfied are students with fully on-line courses?

3) How satisfied are students with partially/hybrid on-line courses?

4) What factors contribute to students' satisfaction with fully on-line courses?

5) What factors contribute to students' satisfaction with partially/hybrid on-line courses?

6) Are learning outcomes of both on-line and face-to-face learning equivalent?

7) How could on-line practices improve?

\section{Materials and Methods}

The study conducted online anonymous surveys using structured questionnaires. The founder of modern research surveys was Paul Felix Lazarsfeld who made considerable contributions to statistical survey analysis. This method is best suited for studies that have individual people as the unit of analysis. Furthermore, survey research has several inherent strengths compared to other research methods, as it is considered to be an excellent tool for measuring a wide variety of unobservable data, such as people's preferences [4] Hence it is considered to be the most appropriate for testing hypothesis of this study. It used multiple tools for the statistical analysis. The first is descriptive statistics to summarize demographic data of students. While another quantitative analysis tool, namely excel, used to explore other data; in addition to keyword analysis used to categorize reasons of satisfaction and dissatisfaction. In addition, the study referred to the importance of survey results as inputs for developing a more effective instructional design approach which is one of the most effective and popular approaches used to design education and training programs starting from needs assessment phase, planning educational program, implementation until program evaluation where satisfaction of stakeholders is a key performance indicator [5].

\section{1) Sample and participant selection}

This research evaluates the success of online educational policy in higher education in Egypt by investigating stakeholders' satisfaction with online learning approaches at a number of Egyptian universities during Covid-19 pandemic 2020. The study targeted 3 types of stakeholders. The first is graduates and undergraduate students enrolled at different academic levels: Freshman, Sophomore, Junior and Senior studying different disciplines in the field of Social Sciences in private universities as well as state universities- Cairo University, Ein Shams University, and Helwan University located in three governorates. This group represents the core focus of the survey analysis where it explores level of students' satisfaction or dissatisfaction and major reasons for each case. Analysis of data is key driver to improve learning practices and boost student retention in academic programs.

The second target group is instructors affiliated to both types of universities as well as freelance academicians. While the third group is quality assurance experts who either currently work as quality auditors at the National Authority for Quality Assurance Accreditation of Education
(NAQAAE), Egypt or NAQAAE former auditors who work as quality assurance advisors. Opinion of this target group is crucial in respect to assessing impact of online learning practices on the students' competencies and meeting intended learning outcomes.

The research used a multi-item designed questionnaires for each category in both English and Arabic language. Random selection tool was used to conduct the surveys. The survey tested the level of satisfaction and whether it differs between private and state universities. Questions also investigated reasons for either satisfactions or dissatisfaction. The main purpose is not only to assess the satisfaction with the newly adopted policy of online learning but most importantly to use the feedback as valid input for developing more well-informed and effective instructional design for distance learning in higher education in Egypt.

\section{LITERATURE REVIEW}

\section{A. Level of Satisfaction and Online Learning in Previous Studies}

Satisfaction as Sener and Humbert described is "a vital element in creating a successful online program [6]. Doris Bollinger, as well, asserted that student satisfaction defined as "the learner's perceived value of their educational experiences in an educational setting" [7] as a key determinant for success of online courses and programs, where there are three main constructs in measuring it, namely: interactivity, instructor and technology related issue [8]. A survey report evaluating ten years of online education in the USA by I. Elaine Allen and Jeff Seaman in 2013, investigated the opinions chief academic officers concerning the nature and extent of online learning in over 2800 colleges and universities. This survey asserted that lack of faculty and employers acceptance on one hand, while lack of students' discipline and low rate of students' retention on the other hand act as major barriers to the growth of online learning [9]. While Kranzow investigated ways to design curriculum structure as a driver to promote students' motivation and to facilitate their participation in online community, which in turn increase satisfaction and boost retention. In this study, Kranzow concluded that mere interaction with technology is never enough to create a motivating online community [10], [11], as it does not ensure cognitive engagement of students. Stimulating interactive discourse on debatable issues is an effective tool in creating a motivating online learning community which contributes to students' sustainable satisfaction [12]. There are many other scholars who surveyed critical factors that contribute to student satisfaction. Sahin, for example, pointed that the extent to which the content is linked to personal experience is a key predictor, in addition to instructor support, followed by active learning and finally, real-life problem-solving [13]. In addition, the technological aspect has been identified as the most significant criteria for satisfaction in some studies, as one study referred to positive perceptions of technology is a key variable followed by innovative learning formats [14]. Moreover, in the study by Palmer and Holt indicated that 'comfort level' in using technology was determined as a key 
driver for online learning satisfaction, while clarity of students' self-assessment against their performance in an online environment comes second [15].

Interactivity was the main pillar Swan highlighted to drive students' satisfaction with online learning [16]. This was further confirmed by Kleinman who, in his study, concluded that highly interactive online learning that promotes interactive learning and meeting learning expectations, fosters' satisfactory online learning community'. He emphasized instructional design as an effective mechanism to set and implement such an interactive environment [17]. In addition, Abel, based on his study on best practices in online learning, identified a list of variables that influence its success, where satisfaction as well as institutional factors including leadership, commitment of faculty members, student support and technology are considered to be highly significant [18].

In addition, very few number of surveys have been conducted prior COVID-19. A survey was conducted on both British University in Egypt and Helwan University to investigate the use of technology in teaching and test various factors that affect students' motivation towards e-learning. It revealed that information technology at universities in Egypt confronts many obstacles. Moodle, as e-learning platform, is increasingly used to deliver e-content and the more interactive features used the motivated undergraduates are for the learning process [19].

Another survey was conducted in 2012 targeting higher education students and academics in Egypt investigating their perception with respect to e-learning and opportunities for improvement. This study was launched as a result of the pressing need for e-learning adoption as a viable alternative to serve an increasing number of students per class. Findings highlighted cultural awareness and absence of accreditation by governmental authorities are two major interrelated challenges [20].

\section{B. Toward Online Learning Policy in Egypt}

Balance of Power in the new international system has dramatically changed shifting from nuclear to peaceful technological capabilities with potentials to improve quality of life [21]. While we are entering the 4th generation of artificial intelligence, the world is witnessing a dramatic shift in means of communications, moving from face-to-face towards virtual communication. Looking at some global indicators, we find that, internet users go beyond 4.7 billion, sold cellular phones exceed 6 million/day, emails sent are over 230 billion/day, 6.5 million blog posts/day, 690 million tweets/day and more than 6.5 billion Google searches/day [22]. Furthermore, video conferencing platforms have attained a frog leap, especially post Covid-19; Zoom Meeting's daily participants jumped from 10 million in December 2019 to more than 200 million in March 2020, hitting more than 500 million April 2020 [23] and interestingly, Google Meet is experiencing speedy boost adding 2 million users every day with a growth rate surpassing $60 \%$ [24]; compared to around 44 million users of Microsoft Teams [25].

With the massive breakthrough of online learning worldwide post Covid-19 pandemic, there has been some skepticism concerning the effectiveness of online learning and its impact on the 'digital graduates' competitiveness versus 'traditional correspondence graduates'. Web-based learning has become an inevitable, yet viable, alternative method to face-to-face education. Although many scholars believe that online programs offer a massive number of students the opportunity for global exposure and promotes curriculum internationalization, traditionally, online degrees in Egypt have never been accredited by the Supreme Council of Universities (SCU) [26].

One of the most growing fields in all forms of education worldwide is distance learning and the widespread of e-learning. It has become an indispensable factor in the mainstream of educational system and hence a key driver to human development if effectively managed. The world has been witnessing a steep growth in adopting fully online learning or provision of a blended approach combining periodic campus-based and online/web-based learning practices- so called hybrid/blended online education. In Egypt, distance learning in education is relatively more recent than in many other countries in the globe. Nevertheless, it is witnessing a fast-growing interest and need; especially in response to Covid-19 pandemic 2020; as most conventional, face-to-face universities are increasingly shifting into fully or hybrid online learning. Undoubtedly, sudden transformation to newly developed online teaching strategies and tools, accessibility, quality and sustainability performance management criteria, confront a lot of skepticism! The reason that stimulated the necessity to investigate a key indicator of success, which is satisfaction of stakeholders with online learning: students, instructors and education quality experts.

With the global pandemic Covid -19, policymakers have come to realize more and more every day the importance of integrating online teaching methods into the educational process. Since March 2020, Egyptian universities have shifted to e-learning, ranging from e-content to fully online courses based on their technological infrastructure and human capital capacities. In process of setting academic requirements to ensure maximum benefits of the new educational system, SCU approved the implementation of a proposed hybrid education system in which students receive a mix of both face-to-face and online classes [27] In addition, the Egyptian Prime Minister amended executive regulations for universities law to accredit online examination assessment - Decision \#1200 Year 2020- where Article 79 stipulates that internal regulations could integrate e-teaching via distance learning system in accordance to the nature of the field of study in the different faculties and institutes; while also allows online examination if required technological capacity is available [28]. Such dramatic transformation in higher education system in Egypt has triggered a pressing need to evaluate key stakeholders' satisfaction with the newly adopted hybrid educational system. This study attempts to assess satisfaction of major stakeholders as a key success factor, reflecting on the online teaching capacities of both state and private universities in meeting intended learning outcomes (ILOs) and clientele needs. In addition, it explores stakeholders' opinion, preferences and readiness as essential inputs for setting instructional design for online learning programs. 


\section{RESULTS}

\section{A. On-line Learning Policy Assessment in Egypt}

The study conducted four surveys: the first targeted university students with a total sample of 577 students in three governorates (Cairo, Giza and Helwan), of which 199 are private universities students, while 378 are state universities students - including Cairo University, Ein Shams University and Helwan University; the second targeted stakeholder is instructors from numerous private and state universities in addition to freelance academicians with a total number of 101; last but not least, the survey explored perception of quality assurance experts in the field of higher education, current or former auditors at National Authority for Quality Assurance and Accreditation of Education (NAQAAE). This section of the study presents surveys' findings.

\section{B. Students Satisfaction Assessment: Private Universities vs. State Universities}

Results of private universities' survey showed no significant difference between genders concerning level of satisfaction. It was very important that the sample represents both genders (42\% males and 58\% females) and different academic levels, especially those who have experienced both on-campus and on-line learning, in order for results to be more valid and generalizable. Similar results are reflected by state universities' survey, where respondents of both genders (23\% males and $77 \%$ females and different academic levels, especially levels that experienced both conventional and online formats showed no significant difference in level of satisfaction (Table I).

TABLE I: ACADEMIC LEVEL

\begin{tabular}{|c|c|c|}
\hline Academic Level & \% (Private Universities & $\%$ (State Universities) \\
\hline Graduated & 6 & 6 \\
\hline Senior & 41 & 13 \\
\hline Junior & 4 & 39 \\
\hline Sophomore & 22 & 38 \\
\hline Freshman & 27 & 4 \\
\hline
\end{tabular}

\section{1) Level of student satisfaction with fully online courses}

TABLE II: LEVEL OF STUdENT SATISFACTION WITH FULLy ONLINE COURSES

\begin{tabular}{lcc}
\hline Level & $\begin{array}{c}\text { \% (Private } \\
\text { Universities }\end{array}$ & $\begin{array}{c}\text { \% (State } \\
\text { Universities) }\end{array}$ \\
\hline Very Satisfied & 11 & 6 \\
Satisfied & 22 & 17 \\
Neutral & 32 & 27 \\
Dissatisfied & 18 & 30 \\
Very Dissatisfied & 17 & 20 \\
\hline
\end{tabular}

Source: Conducted by author, Survey Findings.

By measuring level of satisfaction of private university students, we find that over one third $(35 \%)$ of respondents are divided between being dissatisfied and very dissatisfied compared to an almost the same percentage (33\%) including those satisfied and very satisfied. On the other hand. respondents of state universities' students expressed far more dissatisfaction $(50 \%)$ with fully online learning compared to private universities' counterparts as indicated above $(35 \%)$; while percentage of satisfied respondents was $23 \%$ (Table II), which could reflect lower capacity in shifting from conventional to online learning compared to private universities sample.

2) Level of student satisfaction with blended/hybrid online courses

By measuring satisfaction of students at private universities, with blended/hybrid online courses that combine both online and campus-based learning, percentage of satisfied and very satisfied students, surprisingly, were equal to that of fully online learning (33\%); yet the percentage of 'very satisfied category' dropped from 11 to 8 ; whereas 'dissatisfied' categories dropped to from $35 \%$ to $28 \%$, As for state universities, the study asserted that level of satisfaction improves in case of applying blended/hybrid form of education, where the total percentage of students who were 'dissatisfied' and 'very dissatisfied' with this approach declined to $37 \%$ compared to $50 \%$ with respect to fully online learning. Moreover, analysis highlighted mild increase in the percentage of respondents 'satisfied' and 'very satisfied' with blended form compared to fully online hitting a total of $26 \%$ compared to $23 \%$ respectively (Table III). Hence, the study results clearly reflect more preference for hybrid approach by state university students.

TABLE III: LEVEL OF STUDENT SATISFACTION WITH BLENDED ONLINE COURSES

\begin{tabular}{lcc}
\hline Level & $\%$ (Private Universities & $\%$ (State Universities) \\
\hline Very Satisfied & 8 & 6 \\
Satisfied & 25 & 20 \\
Neutral & 39 & 38 \\
Dissatisfied & 15 & 24 \\
Very Dissatisfied & 13 & 13 \\
\hline \multicolumn{2}{c}{ Source: Conducted by author, Survey Findings }
\end{tabular}

\section{3) Factors that contribute to student satisfaction vs dissatisfaction}

In an attempt to investigate reasons of satisfactions and dissatisfaction, the survey questions presented a number of options to choose from one or more, in addition to the opportunity for students to indicate other reasons. Analysis of private universities' survey asserted that 'easy to use online platform' is the most significant reason for satisfaction (50\%) followed by 'instructors use multiple tools $(41 \%)$; while the lowest rated factor is 'interactive discussions' (24\%). On the other hand, a number of factors contribute to students' dissatisfaction with online learning, where poor internet is ranked the highest $(69 \%)$ followed by lack of IT support (45\%) and the lowest rated reason of dissatisfaction is lack of convenience and lack of application (22\%). Moreover, the study investigates reasons of satisfactions and dissatisfaction of state universities' students with online learning using same questions addressed to private universities students. Analysis indicates remarkable differences between state and private universities students' responses. Although 'convenience' receives almost similar number of responses, yet it is the highest ranked factor of satisfaction for state university students hitting only $35 \%$. In addition, respondents who find 'easy to use online platform' contributes to satisfaction have not exceeded $24 \%$ compared to $50 \%$ of their counterparts in private universities. Whereas both types of students share same perception in ranking poor internet as the highest as a 
main factor contributing to dissatisfaction with online learning approach. However, State universities students assert that lack of interactive discussion is another key reason for dissatisfaction (35\%) (Table IV and V).

TABLE IV: FACTORS THAT CONTRIBUTE TO STUDENT SATISFACTION

\begin{tabular}{lcc}
\hline Factors & $\begin{array}{c}\text { \% (Private } \\
\text { Universities }\end{array}$ & $\begin{array}{c}\% \text { (State } \\
\text { Universities) }\end{array}$ \\
\hline Convenience & 32 & 35 \\
Clarity of Course Content & 27 & 24 \\
Instructors Use Multiple Online & 41 & 16 \\
Tools & 24 & 13 \\
Interactive Discussions & 50 & 24 \\
Easy to Use Online Platform & \multicolumn{2}{c}{ Source: Conducted by author, Survey Findings } \\
\hline \multicolumn{2}{c}{}
\end{tabular}

TABLE V: FACTORS THAT CONTRIBUTE TO STUDENT DISSATISFACTION

\begin{tabular}{lcc}
\hline \multicolumn{1}{c}{ Factors } & $\begin{array}{c}\text { \% (Private } \\
\text { Universities }\end{array}$ & $\begin{array}{c}\text { \% (State } \\
\text { Universities) }\end{array}$ \\
\hline Lack of Convenience & 22 & 28 \\
Poor Course Structure and Unclear & & \\
Material & 33 & 29 \\
Lack of Online Tools & 23 & 16 \\
Lack of Application & 22 & 19 \\
Lack of Interactive Discussions & 27 & 35 \\
Poor IT Support & 45 & 29 \\
Poor Internet Connection & 69 & 60 \\
\hline
\end{tabular}

Source: Conducted by author, Survey Findings

\section{Instructors Satisfaction Assessment}

Results of survey were based on responses of 101 instructors of which $69 \%$ are female, as the target disciplines are within the social science domain where the number of female instructors generally exceeds that of males. In addition, the study reflected viewpoints of a sample of instructors affiliated to private universities $(72 \%)$ and state universities $(26 \%)$ as well as freelance $(2 \%)$ teaching in both undergraduate $(75 \%)$ and postgraduate programs $(25 \%)$.

1) Level of satisfaction with fully online courses vs blended/hybrid courses

Instructors expressed more satisfaction with blended/hybrid online learning compared to fully online approach, as the total percentage of instructors who responded to the question on the level of satisfaction with either very satisfied or satisfied are $54 \%$ for the fully online learning rising to hit $60 \%$ for the blended learning approach. In addition, dissatisfaction decreased from $22 \%$ to $10 \%$ respectively (Table VI).

TABLE VI: LEVEL OF INSTRUCTOR SATISFACTION WITH ONLINE COURSES

\begin{tabular}{lcc}
\hline Level of Satisfaction & \% (Fully Online) & \% (Blended/ Hybrid) \\
\hline Very satisfied & 24 & 16 \\
Satisfied & 30 & 44 \\
Neutral & 24 & 30 \\
Dissatisfied & 17 & 8 \\
Very Dissatisfied & 5 & 2 \\
\hline \multicolumn{2}{c}{ Source Conducted by author, Survey Findings }
\end{tabular}

\section{2) Extent to which online approaches fulfill intended learning outcomes (ILOs)}

Responses of instructors concerning to what extent the two different approaches of online learning meet intended learning outcomes (ILOs) further affirmed preference tendencies toward hybrid approach. Responses of instructors who 'strongly agree' and 'agree' increased from 53\% for fully online to $65 \%$ for hybrid learning and those who 'strongly disagree' and 'disagree' that learning approach achieve ILOs decrease from $23 \%$ to $10 \%$ respectively (Table VII).

\begin{tabular}{lcc}
\multicolumn{3}{c}{ TABLE VII: EXTENT TO WHICH ONLINE APPROACHES FULFILL ILOS } \\
\hline Rating & $\begin{array}{l}\text { \% (Fully } \\
\text { Online) }\end{array}$ & \% (Blended/Hybrid) \\
\hline Strongly Agree & 15 & 19 \\
Agree & 38 & 46 \\
Neutral & 23 & 25 \\
Disagree & 18 & 9 \\
Strongly Disagree & 5 & 1 \\
\hline \multicolumn{2}{c}{ Source: Conducted by author, Survey Findings }
\end{tabular}

\section{3) Factors that contributed to satisfaction with online courses}

By investigating key factors of satisfaction of online courses, all of the suggested alternatives were chosen, yet with different ratings. In addition, they did not suggest additional reasons of satisfaction in the 'others' option. The most agreed upon reason of satisfaction is 'easy to use online platform' (63\% of respondents), followed by 'clarity of course content' (55\%); however, 'convenience' and 'interactive discussions' received $35 \%$ and $31 \%$ respectively, while 'instructors use multiple online tools' scored the lowest (20\%) (Table VIII). While similar to students' opinion 'poor internet connection' came to be one the most significant factor of dissatisfaction (73\%) followed by 'poor IT support' (44\%). In addition, 'lack of interactive discussions' is perceived also to be an alarming weakness (40\%) (Table IX).

\begin{tabular}{lc} 
TABLE VIII: FACTORS THAT CONTRIBUTE TO SATISFACTION \\
\hline Factors & $\%$ \\
\hline Convenience & 35 \\
Clarity of course content & 55 \\
Instructor use multiple online tools & 20 \\
Interactive discussions & 31 \\
Easy to use online platform & 63 \\
\hline \multicolumn{2}{c}{ Source: Conducted by author, Survey Findings }
\end{tabular}

TABLE IX: FACTORS THAT CONTRIBUTE TO DISSATISFACTION

\begin{tabular}{ll}
\hline Factors & $\%$ \\
\hline Lack of convenience & 23 \\
lack of online tools available for instructors & 19 \\
Lack of tools for application & 22 \\
Lack of interactive discussions & 40 \\
Poor IT support & 44 \\
Poor internet connection & 73 \\
\hline \multicolumn{2}{c}{ Source: Conducted by author, Survey Findings } \\
\end{tabular}

\section{Quality Assurance Experts Assessment}

The quality experts survey embraces quality assurance related variables reflecting level of effectiveness in shifting to online learning, conformance to quality assurance standards, extent to which online learning meet ILOs, recommended approach post COVID-19 pandemic as well as perceived strengths and weakness of online learning. Almost $67 \%$ of the experts either 'strongly disagree' or 'disagree' that online learning meet ILOs, while only 33\% 'strongly agree' or 'agree' (Table X). 
TABLE X: EXTENT TO WHICH ONLINE LEARNING MEET ILOS

\begin{tabular}{lc} 
Rating & $\%$ \\
\hline Strongly Agree & 16.67 \\
Agree & 16.67 \\
Neutral & 0 \\
Disagree & 50 \\
Strongly Disagree & 16.67 \\
\hline \multicolumn{2}{c}{ Source: Conducted by author, Survey Findings }
\end{tabular}

With regard to rating how effective universities in shifting to online learning, the study asserts that quality experts believe that private universities have been able to shift more effectively than state universities; where $67 \%$ of respondents 'very agree' or 'agree' that private universities have been able to shift effectively to online format, while only $33 \%$ agree with respect to state universities (Table XI). In addition, dissatisfaction of quality experts with respect to online learning experience at state university has been further reflected by their responses concerning scaling conformance of online learning approach with quality assurance standards, where results indicate that $50 \%$ of quality experts 'disagree' that conformance exists at private universities versus $83 \%$ with respect to state universities (Table XII). Accordingly, $83 \%$ of quality experts asserted that shifting either to fully online or hybrid format, requires changing quality assurance standards (Table XIII). In addition, none of the experts recommended to pursuing fully online learning post COVID-19, compared to $67 \%$ recommending hybrid approach, while $33 \%$ refuted both approaches (Table XIV).

\begin{tabular}{lcc}
\multicolumn{2}{c}{ TABLE XI: EFFECTIVENESS OF SHIFTING TO ONLINE LEARNING } \\
\hline Rating & $\begin{array}{c}\text { \% (Private } \\
\text { Universities }\end{array}$ & $\begin{array}{c}\text { \% (State } \\
\text { Universities) }\end{array}$ \\
\hline trongly Agree & 17 & 0 \\
gree & 50 & 33 \\
Neutral & 33 & 0 \\
Disagree & 0 & 50 \\
Strongly Disagree & 0 & 17
\end{tabular}

Source: Conducted by author, Survey Findings

TABLE XII: CONFORMANCE TO QUALITY ASSURANCE STANDARDS

\begin{tabular}{lcc}
\hline Rating & $\begin{array}{c}\text { \% (Private } \\
\text { Universities }\end{array}$ & $\begin{array}{c}\text { \% (State } \\
\text { Universities) }\end{array}$ \\
\hline Strongly Agree & 0 & 17 \\
Agree & 33 & 0 \\
Neutral & 17 & 0 \\
Disagree & 50 & 83 \\
Strongly Disagree & 0 & 0 \\
\hline \multicolumn{2}{c}{ Source Conducted by }
\end{tabular}

Source: Conducted by author, Survey Findings

TABLE XIII: SHIFTING TO FULLY ONLINE OR HYBRID COURSES REQUIRES CHANGING QUALITY ASSURANCE STANDARDS

\begin{tabular}{lc}
\hline Response & $\%$ \\
\hline \multirow{2}{*}{ Yes } & 83 \\
No & 17 \\
\hline & Source: Conducted by author, Survey Findings
\end{tabular}

TABLE XIV: RECOMMENDED ONLINE LEARNING METHODS POST-COVID-19

\begin{tabular}{lc}
\hline Recommended Online Learning Methods & $\%$ \\
\hline Pursue Applying Fully Online Learning & 0 \\
Pursue Applying Hybrid Learning & 67 \\
None & 33 \\
\hline
\end{tabular}

Source: Conducted by author, Survey Findings

\section{DISCUSSION}

The questionnaire attempted to investigate quality experts' evaluation of points of strengths and weaknesses and hence they were asked about the advantages and disadvantages of e-learning associated with quality assurance standards. This part presents a record of the factors they consensually agree on.

\section{A. Quality-Related Online Positive Factors}

- Upgrade teaching and learning standards and promote innovation and creativity.

- Create an interactive learning environment and offer diverse sources of information and experiences.

- Equip faculty members, teaching assistants and students with necessary technical skills for using digital educational technologies, which are general skills of the ILOs.

- Create educational platforms to organize and manage work systems of educational institutions.

- Encourage self-learning and participatory learning which create new learning methods.

- Build-in flexibility in several aspects of the educational process such as flexibility in time and content.

- Ease of two-way communication between the students and both faculty members and teaching assistants.

\section{B. Quality-Related Online Negative Factors}

- Lack of students' participation in various activities.

- Lack of clear assessment criteria for measuring e-learning curricula competency.

- Lack of clear policies and procedures for e-learning quality audit and development tools.

- Poor internet in most universities.

- Lack of conformance of adopted and accredited e-learning assessment methods

- with quality standards.

- Poor digital infrastructure hinder achieving quality standards.

- Implementing one method of learning targeting diverse students.

- Lack of interaction.

- Lack of acquired professional skills.

- Unfair students' evaluation methods.

\section{Limitations}

Total number of higher education students in Egypt exceed 3 million in 27 governorates [29] and hence it was difficult to cover a representative sample as the encompassed only 577 students in three governorates (Cairo, Giza and Helwan). In addition, as a result of the limited time span as online learning format has been recently adopted in Egypt, since Covid-19 pandemic, it has been impossible to test the impact; which calls for future further studies to investigate long term impact of online learning that could be conveyed by investigating competency and employability of digital learning alumni.

\section{CONCLUSIONS}

Looking at global Indicators, the world is unprecedentedly transforming from conventional into virtual communication, 
where interactions, relations, transfers, education, work-system, institutions, etc. are moving towards virtual digitalization. We realize more and more every day the decisive need to set the building blocks for this new digital era; amongst are: -coming to grips with the fourth industrial revolution's exponential changes; - developing adequate and catalytic infrastructure; - human capital capacity building as the backbone for creating a 'borderless interactive digital citizen'. In case, any of the aforementioned pillars fail, widening the gap between the society and the state as well as between the state and the world would take place. Most international universities have shifted from conventional learning to digital platforms.

Internationalization of education and knowledge are perceived as cornerstone for achieving sustainable development. Moving towards digitalization has become inevitable. Educational institutions have come to grips with exponentially evolving globalization measures in education in order to survive fierce competition and challenges that the 4th industrial revolution has triggered. Looking into the case of the Egyptian universities online learning experience, specifically in the field of social sciences, the study asserts that tested private universities have been more effective than state universities in shifting from conventional learning to online learning. In addition, the study observes that both internet infrastructure and IT support appear to be common significant environmental variables. Furthermore, level of student-instructor interaction, utilization of multiple digital tools as well as feasibility of application are identified as major reasons of dissatisfaction and hence these critical factors should be highly considered in instructionally designing online programs and curricula. In general, the majority of all target groups recommended hybrid format to bridge the gap between conventional and fully online learning with respect to interactions and hand-on learning. In light of the survey results, the study presents the following recommended policies with the purpose to further narrow this gap, enhance students' satisfaction to sustain retention and improve meeting higher education quality measures:

- Legal Framework: amend laws and regulations governing higher education as to set performance standards concerning the leaning process and assessment to ensure both equity and competency as well as setting academic requirements for online programs accreditation.

- Digital Infrastructure: develop internet infrastructure in all regions in Egypt.

- Quality Assurance: review and amend national academic reference standards and requirements stipulated by the National Authority for Quality Assurance and Accreditation of Education (NAQAA) to be more integrated with international measures in the new digital age.

- Human Capital Capacity Building: assess training needs of academic staff to upgrade their knowledge and skills to effectively utilize digital platforms, utilize multiple online teaching tools and conduct highly interactive online activities.

- Multilateralism: promote collaboration with international universities to offer students the opportunity for a low-cost international exposure, internationalize academic curricula and offer internationally competent graduates.

\section{CONFLICT OF INTEREST}

The author declares no conflict of interest.

\section{REFERENCES}

[1] Digital 2021: Global Overview Report - DataReportal - Global Digital Insights. [Online]. Available: https://datareportal.com/reports/digital-2021-global-overview-report

[2] The COVID-19 pandemic has changed education forever. This is how World Economic Forum 2020. [Online]. Available: https://www.weforum.org/agenda/2020/04/coronavirus-education-glo bal-covid19-online-digital-learning/

[3] A. Almashat, Virtual World...Coming. Al Ahram Al Iktisadi, April 19, 2020, p. 42.

[4] P. F. Lazarsfeld, Qualitative Analysis; Historical and Critical Essays, Allyn and Bacon, 1972.

[5] R. Noe, J. Hollenbeck, B. Gerhart, and P. Wright, Fundamentals of Human Resource Management, 6th edition, McGraw-Hill Education: New York, NY, 2015.

[6] J. Sener and J. Humbert, "Student satisfaction with online learning: An expanding universe," Elem. Qual. Online Educ. Pract. Dir., 2003, pp. 245-260.

[7] D. U. Bolliger and E. A. Erichsen, "Student satisfaction with blended and online courses based on personality type," Can. J. Learn. Technol., 2013, vol. 39, no. 1 .

[8] D. U. Bolliger, "Key factors for determining student satisfaction in online courses," Int. J. E-Learn, 2004, vol. 3, no. 1, pp. 61-67.

[9] I. E. Allen and J. Seaman, "Changing course: Ten years of tracking online education in the United States," Sloan Consortium, 2013.

[10] J. Kranzow, Faculty Leadership in Online Education: Structuring Courses to Impact Student Satisfaction and Persistence, 2013, vol. 9, no. 1, p. 9 .

[11] D. R. Garrison and M. Cleveland-Innes, "Facilitating cognitive presence in online learning: Interaction is not enough," Am. J. Distance Educ., 2005, vol. 19, no. 3, pp. 133-148.

[12] M. Pinto and W. Anderson, "A little knowledge goes a long way: Student expectation and satisfaction with hybrid learning," Journal of Instructional Pedagogies, vol. 10, pp. 65-76, 2013.

[13] I. Sahin, Predicting Student Satisfaction in Distance Education and Learning Environments, 2007.

[14] J. Drennan, J. Kennedy, and A. Pisarski, "Factors affecting student attitudes toward flexible online learning in management education," $J$. Educ. Res., 2005, vol. 98, no. 6, pp. 331-338.

[15] S. R. Palmer and D. M. Holt, "Examining student satisfaction with wholly online learning," J. Comput. Assist. Learn, 2009, vol. 25, no. 2, pp. 101-113.

[16] K. Swan, "Virtual interaction: Design factors affecting student satisfaction and perceived learning in asynchronous online courses," Distance Educ., 2001, vol. 22, no. 2, pp. 306-331.

[17] S. Kleinman, "Strategies for encouraging active learning, interaction, and academic integrity in online courses," Commun. Teach., 2005, vol. 19, no. 1, pp. 13-18.

[18] R. Abel, "Implementing best practices in online learning," EDUCAUSE Quarterly, vol. 28, no. 3, pp. 75-77.

[19] S. El-Seoud et al., E-Learning and Motivation Effects on Egyptian Higher Education, 2013, p 695.

[20] S. Gamal and R. Aziz, "Improving higher education in Egypt through e-learning programs: HE Students and senior academics perspective," Int J Innov. Educ., 2012, vol. 1, pp. 335-361.

[21] A. Almashat, New Asian-South International System, April 5, 2020.

[22] (December 26, 2020). Worldometer - real time world statistics. Society \& Media. [Online]. Available: https://www.worldometers.info/

[23] M. Iqbal. (2020). Zoom Revenue and Usage Statistics. [Online]. Available: https://www.businessofapps.com/data/zoom-statistics/

[24] P. Moorhead, "Google is adding two million new meet users each day and i'm not surprised," Forbes, April 13, 2020.

[25] G. Sevilla. Zoom Vs Microsoft Teams Vs. Google Meet: Which Top Videoconferencing App is Best, 2020.PCMag.com - Technology Product Reviews, News, Prices \& Tips. [Online]. Available: https://me.pcmag.com/en/

[26] Egypt's covid-19 shift to online learning is spurring a push towards fully-online degrees. But more regulation and resources are needed for it to work. Enterprise 12 October, 2020. [Online]. Available: 
https://enterprise.press/stories/2020/10/12/egypts-covid-19-shift-to-on line-learning-is-spurring-a-push-towards-fully-online-degrees-but-mo re-regulation-and-resources-are-needed-for-it-to-work-23107

[27] Supreme Council of Universities. [Online]. Available: https://scu.eg//

[28] Prime Minister Decision \# 1200, Year 2020, Issue 24.Official Gazette EgyptToday. [Online].

Available: https://www.egypttoday.com/Tag/8602/Official-Gazette

[29] Central Agency for Public Mobilization and Statistics. (2020). [Online]. Available: https://www.capmas.gov.eg/

Copyright $(92021$ by the authors. This is an open access article distributed under the Creative Commons Attribution License which permits unrestricted use, distribution, and reproduction in any medium, provided the original work is properly cited (CC BY 4.0).

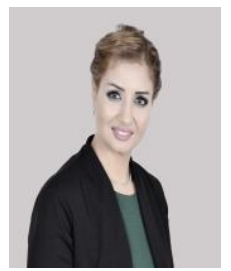

Salwa Thabet Mekky holds the $\mathrm{PhD}$ in public administration, Sadat Academy 2009, the MA in business administration (1999) and the BA in business administration (1994) from the American University in Cairo. The main area of study is public policy and digitalization.

She works as an associate professor of public administration and acting vice dean for education and students affairs, Faculty of Economics and Political Science (FEPS), Future University in Egypt (FUE), Cairo, Egypt. She is also the deputy chairman of FEPS Quality Assurance Unit. She serves as the academic coordinator of a number of international joint programs and courses, such as Seattle University-FUE Social Media Program, University of Washington-FUE Great Debate, Soliya Connect Program and Young Arab Voices initiated and sponsored by the British Council. She is also Public Policy Consultant for the UNICEF, Egypt.

Dr. Mekky is the chairman of Abu Al-Soud Association for Local Development (ASSDA), an NGO that has been established since 1998. She was the Executive Director of Cairo Center for Human Development (CCHD) 2012-2016. She worked in the area of civic education since 2011 in many regions in Egypt. 